\title{
Flood Monitoring and Flood Risk Assessment in Agenebode, Edo State, Nigeria
}

\author{
Juliet I. Akpejiori ${ }^{1}$,Jacob O. Ehiorobo ${ }^{2}$, OsadolorC.Izinyon $^{3}$ \\ ${ }_{(}^{1}$ Department of Geomatics, University of Benin, Nigeria \\ $\left({ }^{2}\right.$ Department of Civil Engineering, University of Benin, Nigeria \\ $\left({ }^{3}\right.$ Department of Civil Engineering, University of Benin, Nigeria
}

\begin{abstract}
Flooding is a serious natural disaster that has become a recurrent event in many parts of the world causing huge loss of lives and properties. This study analyses flood risk potential in Agenebode, Edo state, Nigeria. Flood frequency analysis was carried out on discharge data from the River Niger at Onitsha from 1960-2006 as the discharge from this river is the primary cause of flooding of the study area. Log-Normal, Log-Pearson Type III and Gumbel probability distribution models were used to test for the most appropriate projection for discharge for different return periods.From the analysis, Log-normal distribution was selected as the most appropriate probability distribution for the series in order to determine projected flows for the river for different return periods. The rainfall pattern for the study area was analysed using gauge values for the period 1983-2010. Flood hazard assessment was carried out with the aid of ArcMap using the topographical feature data of the area, Digital Elevation Model obtained from Shuttle Radar Topographical Mission (SRTM) hole-filled seamless data and historical records of the previous flood occurrence. A flood hazard map produced indicated that about 1.8 $\mathrm{km}^{2}(72 \%$ of the total built-up area) of the area is at risk of flooding putting approximately 481 people at direct risk of flooding. This information is useful for providing ameliorative resources for the inhabitants in the event of a flood occurrence.
\end{abstract}

Keywords: Digital Elevation Model, Flood frequency, Flood hazard,Geographical Information System, Return period

\section{INTRODUCTION}

A flood is an overflow of water that submerges or "drowns" land. It is an overflow of a great body of water over land that is not usually submerged. Flooding is now an increasing problem due to a rising global temperature resulting in increased rainfall, evaporation of water bodies and glacier melt, causing an increase in sea level which then inundates lands near to such bodies [1]. They can, however, turn into disasters, causing widespread damage, health problems and even deaths. They have helped to shape natural landscapes, habitats and ecosystems in floodplains, wetlands and other lowlands [2]. Floods can also occur in rivers, when flow exceeds the capacity of the river channel, particularly at bends or meanders. Some floods develop slowly, while others such as flash floods can develop in just a few minutes and without visible signs of rain.

Flooding is a serious ecological problem worldwide. Across the world, floods have posed tremendous danger to many lives and properties. It is reported that floods cause about one-third of all deaths, one-third of all injuries and one-third of all damages from natural disasters [3], Asia and the Middle East being the worst hit. Countries such as Bangladesh, Pakistan, Nepal and India have experienced the worst occasions of flooding of all time. Other recent events are the Tsunami of 2011 in Asia, and Hurricane and flooding of the Philippines in 2013. In Nigeria, the pattern is similar with the rest of the world. Nigeria experienced a devastating flood occurrence in 2012. Flooding in various parts of the country have forced millions of people from their homes, destroyed businesses, polluted water resources and increased the risk of diseases especially in rural areas [4,5,6]. About 22 out of the 36 states of the Federal Republic of Nigeria have had one or more flood occurrences in the last two decades [7].

Floods often happen over flat or low-lying areas when the ground is saturated and water either cannot run off, or cannot run off quickly enough to stop accumulating. This may be later followed by a river flood as water moves away from the areal floodplain into local rivers and streams. Flooding is a natural event and could be a recurring event for a river or stream. Flooding could also be as a result of heavy or continuous rainfall exceeding the absorptive capacity of soil and the flow capacity of rivers, streams, and coastal areas[8]. Other causes of flooding include fluvial flooding, groundwater, surface water runoff and sewer flooding. A flood risk assessment is an assessment of the risk of flooding, 
particularly in relation to residential, commercial and industrial land use. It is submitted alongside planning applications in areas that are known to be at risk of flooding to prevent inappropriate development in high risk areas and to direct development away from areas at highest risk. Flood risk assessments also help to provide insurers with a more detailed assessment of flood risk at a location to aid in arriving at appropriate insurance premiums. Monitoring and assessing a river basin for its vulnerability to flood helps in planning for any unprecedented flooding and help responsible agencies to plan effectively for hazards associated with flooding hence a proper flood risk mapping will assist in delineating areas prone to flood and in achieving a reliable and effective land use planning of the area. There is therefore the need to plan and prepare for a future occurrence of this disaster by way of assessing the extent of the flooding and monitoring, in order to provide a means of wading off flooding in the future so as to direct land planning authorities on the best way to channel development of the area in a way to avoid huge losses during a flood event.

Agenebode is an important urban town in Nigeria located along the banks of River Niger. This predisposes the community to flooding. Its inhabitants experienced untold hardships, loss of lives and properties due to the flooding which occurred in September 2012. The flood resulted in destruction of crops, livestock and farmlands.

\subsection{Aims and Objectives}

To the best of the knowledge of the authors, no flood risk assessment study has been conducted for the study area to date hence the aim of the study is to carry out an assessment of flood risk at Agenebode located in Edo state, Nigeria using a combination of flood risk analysis for some given return period and flood hazard analysis using ArcGIS software.

\section{The specific objectives are:}

a) To carry out flood frequency analysis of the flood discharge data using selected probability distributions models (Log-Normal, Log-Pearson Type III and Gumbel)

b) Apply the selected probability distribution models in estimating flood quartiles for selected return periods ( $\mathrm{T}=2$ years, 5 years, 10 years, 25 years, 50 years, 100 years and 200 years.

c) Evaluate the potential for flooding occurring within the lower Niger basin at Agenebode and assess the likely environmental effect.

d) Prepare flood hazard map for the study area using ArcGIS to aid in early warning in the event of future flooding.

\subsection{Description of the Study Area}

The study area lies between latitudes $7^{\circ} 03^{\prime} 15^{\prime \prime} \mathrm{N}$ to $07^{\circ} 09^{\prime} 15^{\prime \prime} \mathrm{N}$ and longitudes $06^{\circ} 39^{\prime} 42^{\prime \prime} \mathrm{E}$ to $6^{\circ} 45^{\prime} 00^{\prime \prime} \mathrm{E}$ respectively (Fig. 1). It is located on the lower course of the River Niger. The area is generally a lowland area, the highest elevation being a little above $200 \mathrm{~m}$. The population is concentrated at the river bank which increases the risk of flooding to the inhabitants. In this region, the river basin formation is a layer of sedimentary origin which is Cretaceous [9]. The rainfall pattern is such that it has a high-water period that begins in May or June and ends in October. The driest periods are at the beginning and end of the year that is October to December and January to April. The soil is characterized by thick ferralitic soils which is extensive over the major part of the River Niger basin in Nigeria. The vegetation consists mainly of scattered cultivation with the presence of light forest and scrubland. Some parts are of the savannas and orchard bushes type of vegetation [9].

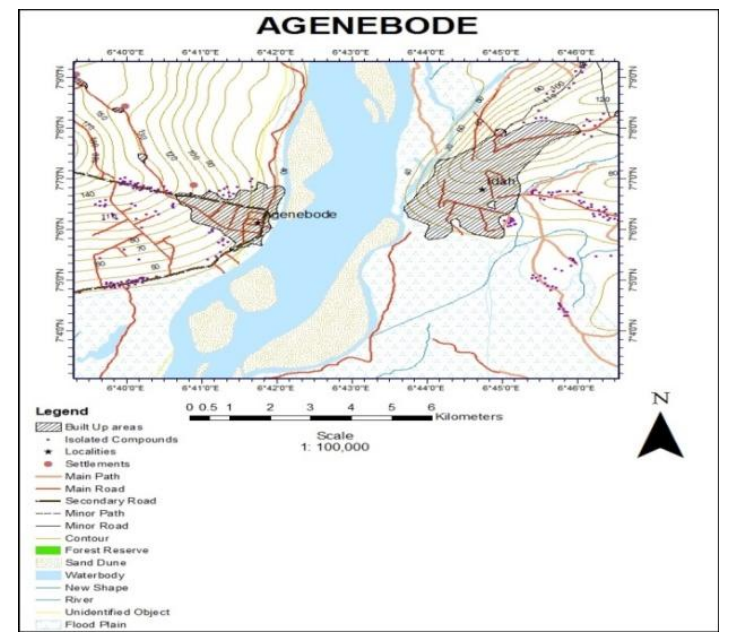

Figure 1:Topographical map of the study area

\section{METHODS}

\subsection{Flood Probability}

Probability in relation to flood studies refers to determining the probability of occurrence of a flood event in order to calculate the design flood. There are different methods of determining flood probability. For this study, flood frequency analysis was undertaken which makes use of observed annual peak flow discharge data to calculate statistical information such as mean values, standard deviations, and skewness and recurrence intervals. Flood frequency analysis was used to estimate the flood quartiles that can occur in a given time interval and to know the peak flow expected over different periods at the location. This information is used by a hydrologist or civil engineer to determine the size of a hydraulic structure for controlling flood and is also used by urban planners and civil engineers to determine the 
best locations for infrastructures needed for development of the area.

A flood frequency analysis was carried out on discharge data (annual maximum series) from the River Niger at Onitsha an area within the same river basin, for the period 1960-2006 and applying three flood frequency probability distribution models namely log-normal distribution, log-Pearson Type III distribution and Gumbel distribution. The flood quartiles $\left(\mathrm{Q}_{\mathrm{T}}\right)$ of return periods of 2, 5, 10, 25, 50, 100 and 200 years respectively were computed using each of these distributions. These discharges represent the expected discharges once in every specific return period in years. Recurrence intervals were obtained using the Weibull formula $[10,11]$.

$T_{R}=\frac{n+1}{m}$

Where $\mathrm{n}=$ number of recorded years for the data, $m=$ rank of each year obtained arranging the data in descending order of magnitude with the highest value getting a value of 1 , the next larger getting 2 and so on. The general equation used for deriving expected discharges $\mathrm{Q}_{\mathrm{T}}$ for the different return periods[12] is:

$\mathrm{Q}_{\mathrm{T}}=\bar{Q}+K \sigma$

Where $\bar{Q}$ is the mean of the discharge data, $\mathrm{K}$ is the frequency factor corresponding to each return period for the different distributions and $\sigma$ is the standard deviation for the discharge data calculated from:

$\sigma=\sqrt{\frac{\sum(Q-Q)^{2}}{n-1}}$

\subsection{Flood plain delineation}

Flood plain delineation is the process of determining inundation extent and depth by comparing river levels with ground surface elevations. The method consists of the following basic steps [13]:

1. River stages are observed or water levels are simulated from surface water models at different points or locations along the river

2. Topographic map is collected for use if available or may be prepared as required.

3. Water levels are marked on the topographic map

4. Water levels are extended until impeded by higher elevation

5. The contour lines are traced to delineate the flood plain

6. The flood extent maps are then manually prepared.

However, in recent times, estimation of flooded area is now undertaken by means of remote sensing (RS) techniques along with Geographic Information System (GIS) data. When flood plain is to be delineated by remote sensing techniques, it is necessary to have satellite imagery.

\subsubsection{Flood Hazard Mapping}

Flood hazard mapping for this study was achieved using remote sensing and GIS techniques. Remote sensing was used as a tool for providing an overview of the distribution of flood events and could be used to measure and analyze the extent to which the flood has occurred over the flooded area. This was achieved through the provision of spatial data such as high resolution satellite imageries which are used in run-off analysis, flood forecasting and flood hazard mapping by the application of the Geospatial Information System (GIS) technology. This technology combines satellite information and observation obtained from the ground to generate models of present and future occurrences of flood events. These models provide a measure of assessment of damages due to current and future flood events.Remote sensing technology along with GIS has become the key tool for flood monitoring in recent years. The central focus in this field revolves around delineation of flood zones and preparation of flood hazard and flood risk maps for the vulnerable areas.Remote sensing techniques generate images, land information such as slope; elevation and land cover data which are then manipulated in GIS environments to create databases with other measured parameters from the ground surface in order to analyze problems of interest and proffer solutions to such issues.

Due to the high cost of imagery required for a study such as LIDARwhich incorporatesland cloud cover data in this part of the world, a low resolution USGS/NASA SRTM DEM from SRTM websitewith spatial resolution of the GeoTiffs as $6000 \times 6000$ pixels was the best available option for generation of maps for the study.

\section{ANALYSIS AND RESULTS 3.1 Rainfall Pattern}

The study of the rainfall pattern is important because it is the remote cause of flooding in this area. It is essential that rainfall pattern is adequately studied as this is the main cause of flooding especially in this part of the world. The rainfall data used for this project was that of Auchi, which is an adjoining city to the study area, (about $47 \mathrm{~km}$ from the study area and is located in the same watershed as Agenebode) obtained from Nigerian Meteorological Agency spanning 28 years from year 1983 to 2010.The total rainfall volumes for each month of the years were obtained for the period and these were plotted with Microsoft Excel spreadsheet application. The rainfall pattern is such that it peaks in May and September. The driest periods are at the beginning and end of the year that is October to December and January to April. 


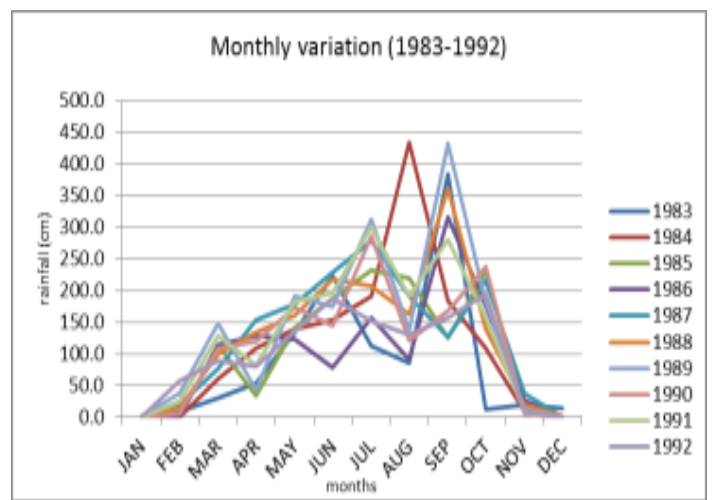

Figure 2a

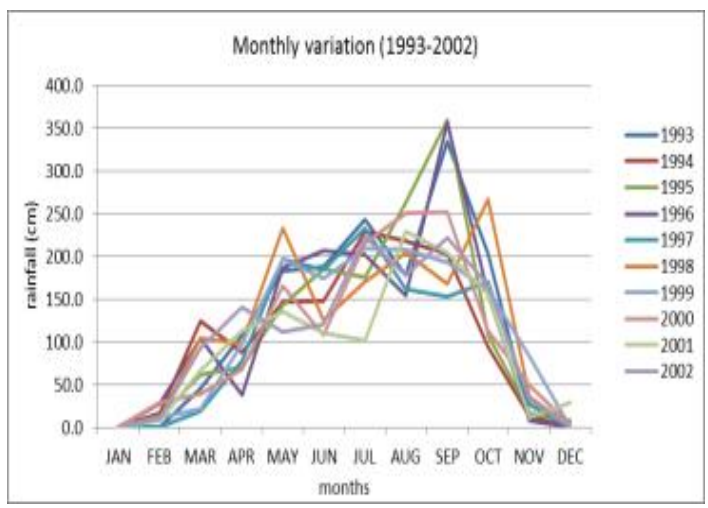

Figure 2b

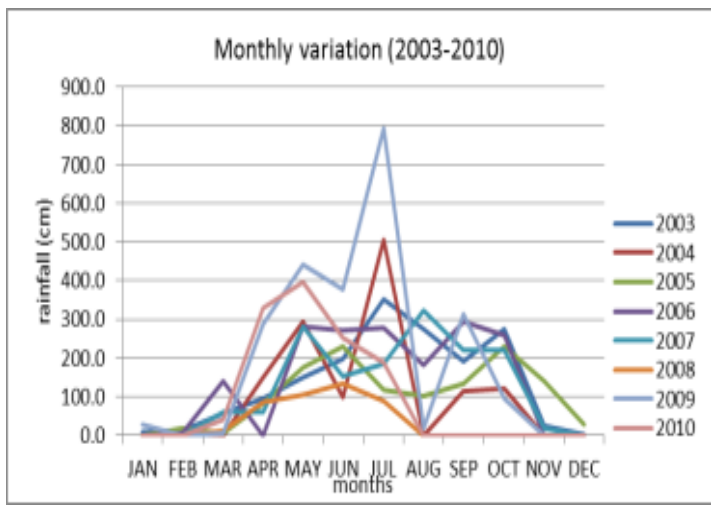

Figure 2c

Figure 2a-2c: Monthly variation of rainfall

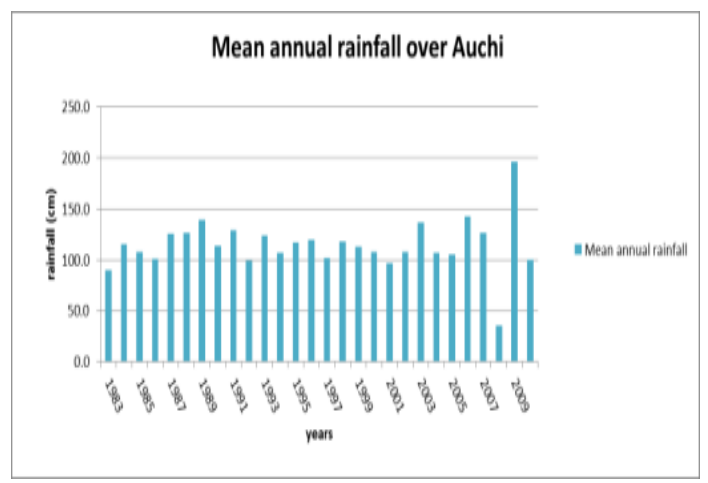

Figure 3a

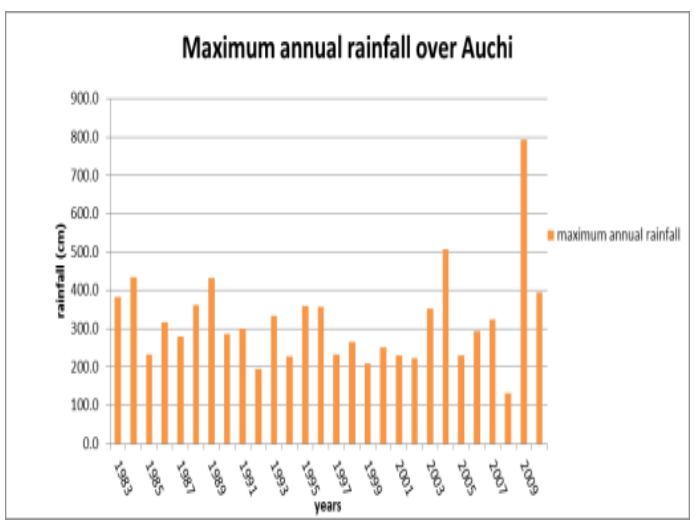

Figure 3b

Figure 3:Graphs showing the mean and maximum distribution of rainfall from 1985-2010

\subsection{Flood Frequency Analysis}

The discharge data obtained were subjected to three frequency distributions (Log-normal, LogPearson and Gumbel) in order to derive probability of occurrences based on the discharge of the river at different return periods. The results are shown below. Based on the information below, the Log-normal distribution which is more consistent in providing higher quantile estimates for higher return periods was selected as more reasonable for conducting the analysis and was thus utilized as the most appropriate flood frequency distribution for the location data.

\subsubsection{Comparison of the applied probability distributions}

In this study, the discharge data obtained were subjected to three frequency distributions analysis (Log-normal, Log- Pearson and Gumbel) in order to derive probability of occurrences based on the discharge of the river at different return periods of $2,5,10,25,50,100$ and 200 years return period frequency analysis based on annual maximum series.

Table 1 presents the quantile estimates obtained for the specified return periods by fitting the three probability distribution models to the observed flood data and the computed percentage deviations of the Log Pearson Type -III and Log -Normal quantile values from their corresponding Gumbel distribution values at the given return periods.

The results show that the Log-normal distribution appears to be the most appropriate flood frequency distribution for this region. It has the largest discharge values among the three distributions tested on the sample data and the most consistent with respect to the return periods the flows represent. 
Table 1: Discharges derived from the probability distributions and their percentage deviation

\begin{tabular}{|c|c|c|c|c|c|}
\hline $\begin{array}{c}\text { Return } \\
\text { Period } \\
\text { Years })\end{array}$ & $\begin{array}{c}\text { Log- } \\
\text { Pearson } \\
(\text { LP) }\end{array}$ & $\begin{array}{c}\text { Log- } \\
\text { normal } \\
(\text { LN) }\end{array}$ & $\begin{array}{c}\text { Gumbel } \\
(\text { GEV) }\end{array}$ & $\begin{array}{c}\% \\
\text { Devia- } \\
\text { tion of } \\
\text { LN } \\
\text { from } \\
\text { GEV }\end{array}$ & $\begin{array}{c}\% \\
\text { Devia- } \\
\text { tion of } \\
\text { LP } \\
\text { form } \\
\text { GEV }\end{array}$ \\
\hline 2 & $17,770.06$ & $14,532.02$ & $15,615.80$ & 6.94 & -13.79 \\
\hline 5 & $23,541.41$ & $24,712.70$ & $21,784.48$ & -13.44 & -8.07 \\
\hline 10 & $25,137.06$ & $32,615.24$ & $25,868.49$ & -26.08 & 2.83 \\
\hline 25 & $26,007.77$ & $43,839.25$ & $31,028.53$ & -41.29 & 16.18 \\
\hline 50 & $26,271.51$ & $53,069.39$ & $34,857.14$ & -52.25 & 24.63 \\
\hline 100 & $26,387.73$ & $62,999.24$ & $38,656.67$ & -62.97 & 31.74 \\
\hline 200 & $26,437.70$ & $73,756.70$ & $42,442.60$ & -73.78 & 37.71 \\
\hline
\end{tabular}

From Table 1above, it can be seen that values derived from the log-normal distribution are most appropriate for the flood. The percentage deviation of log-normal predicted values from the Gumbel Extreme value distribution values range from $-73.78 \%$ at $T_{R}=200$ years to $6.94 \%$ at $T_{R}=2$ years showing that it is suitable for larger return periods. Apart from the 2- year return period, the log-normal distribution predicted higher discharge values than that from Gumbel Distribution which makes it much more suitable for design of flood control structures as design of these structures require larger return periods in order to mitigate against the effect of floods for a long period of time and save cost of rebuilding in the event of failures which arise as a result of using lower design values. It can be also seen that the percentage deviation of Log-Pearson Distribution values from Gumbel Distribution values range from $-13.79 \%$ at 2 years to $37.71 \%$ at 200 years. For very low periods (up to 5 years), Log-Pearson values are a little higher than that for Gumbel Distribution. This implies that if a lower design value is required for up to 5 years, Log -Pearson type III is suitable but not economical. It can be inferred that since the percentage deviation for Log-Pearson distribution is a lot higher compared to that for Log-normal distribution, it would be unsuitable for predicting design floods. Log- Normal distribution is very suitable as a large data range was employed. Gumbel Distribution can also be used but it would not give the maximum values required for long lasting structures.

\subsection{Flood Hazard Delimitation and Delineation of Agenebode}

A flood risk map gives a pictorial view of how parts of an area will be affected by inundation in the event of a flood event. This is based on many different criteria which are normally selected by the assessor based on the type of terrain considered. ArcMap was used in deriving this map using acquired data on the area in the form of topographical maps, raster images, Digital Elevation Models and ground data. In this analysis, historical data was used as part of the data in preparation of the hazard map.

The study area was delineated using a topographic map at scale 1 in 50,000 obtained from the Ministry of Land and Surveys, Edo state, Nigeria. A digital map in ArcGIS format was created showing the features on ground. A Digital Elevation Model (DEM) was downloaded from the Internet on the Shuttle Radar Topographical Mission (SRTM) website and was then used to generate contours, hillshade, slope and Triangulated Irregular Network (TIN) for the area showing the topography of the area. These were done using ArcMap v9.3. The results are presented in Figures 4, 5 and 6 respectively below.

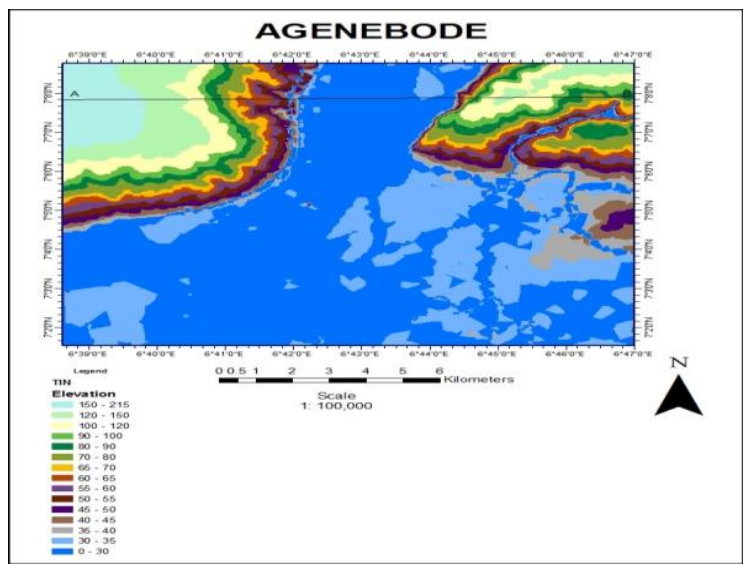

Figure 4:Triangulated Irregular Network from Digital elevation model (DEM)

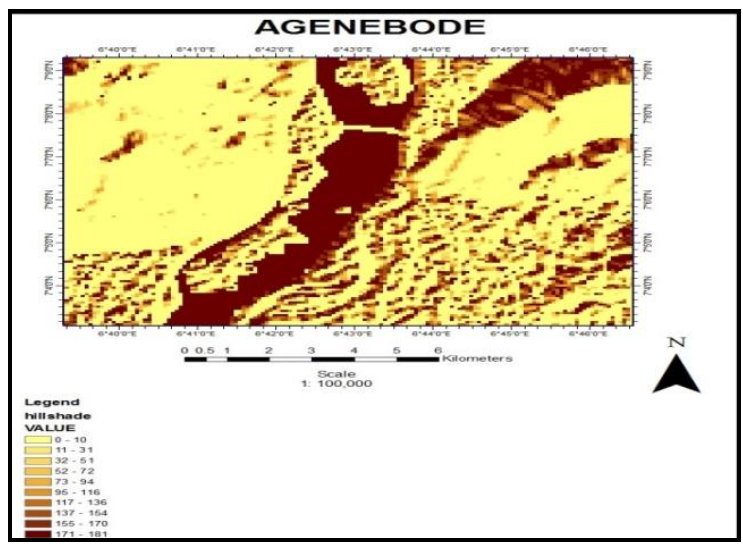

Figure 5:Hillshade of study area from Digital

Elevation Model

Based on information gathered on the previous flood occurrence in 2012, the level of flooding was about $45-50 \mathrm{~m}$. The areas covered by this elevation were all covered by flood. However, based on the topography of the area, it is predicted that an elevation of $60-65 \mathrm{~m}$ is quite safe and presents a lower risk of flooding due to the river. Any area below this range is therefore considered to be at risk of flooding. 


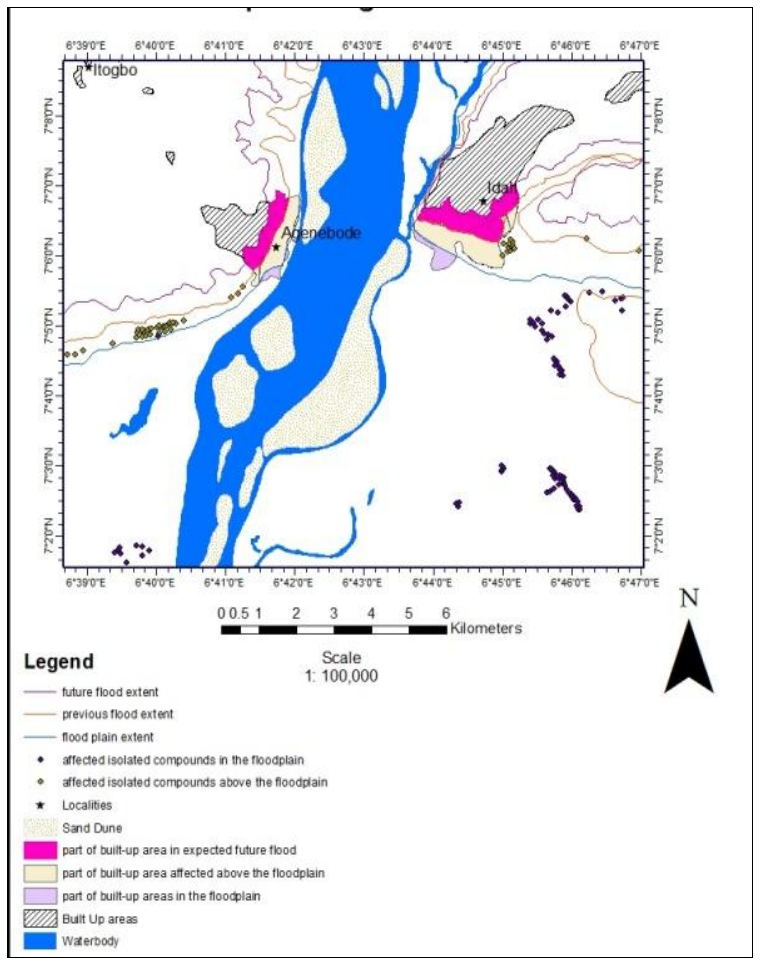

Figure 6:Flood hazard map

From the flood hazard map generated(Figure 6), it can be seen that about $1.05 \mathrm{~km}^{2}(42 \%$ of the total built-up area) of Agenebode were affected by the flood as seen from the map generated. This consists of areas above and below the floodplain elevation. The built-up area affected on the floodplain region is about $0.15 \mathrm{~km}^{2}(6 \%$ percent of the total built-up area).In deriving the number of inhabitants affected, the population density of the area was used which was found to be 129 people per square kilometer (National Population Commission 2006 Census Data, 2010). Applying this to the area affected, 133 people in the built-up area were affected by the previous flood. Thirty-six isolated compounds were also covered by flood. Assuming a household size of 5 - 7 people, 252 people in isolated compounds were displaced by the flood. This brings the estimated total number of families affected by the flood of August 2012 to about 55 families.

Given that a reasonable level of protection of $60-65 \mathrm{~m}$ elevation is assumed to have a low probability of flooding, the projected area in anticipation of future flooding is an area of 0.74 $\mathrm{km}^{2}(30 \%$ of the built-up area) in addition to the already projected area of $1.05 \mathrm{~km}^{2}$ of the previous flood extent in the built-up area (a total of $1.79 \mathrm{~km}^{2}$, which is about $72 \%$ of the built-up area). This represents the extent of the built-up area which will be inundated in the event of a future flood. The additional amount of people who are at risk of future flooding is about 96 people (a total of $\mathbf{4 8 1}$ people which is approximately 69 families).

\section{CONCLUSION}

The following can be concluded from the results of the study:

1. The Flood Map provides a wealth of flood hazard and risk informationwhich has a great potential to reduce damage to a great extent especially as flood could be treated as hazard in consideration of the fact that it poses threat to humans, their properties and their welfare [14].

2. This study entailed conducting flood frequency analysis of the River Niger subjecting acquired discharge data from 1960-2006 to three probability distributions in order to find the appropriate distribution to obtain design discharge values for constructing flood control structures along the river bank. It was shown that three distributions could be used but on different scenarios. Log-Normal Distribution can be used for larger return periods of up to 200 years while Log-Pearson Type III and Gumbel distributions could be used for return periods of up to 5 years. Log-normal would be a better choice in this area as cost is the first factor to consider in construction. The estimates of flood discharges from Log-normal distribution would be more reliable for the design and operation of vital infrastructures and for flood risk management and planning as well as for flood hazard mapping.

3. Identification and delineation of areas prone to flood hazard constitute an essential step of a flood plain management scheme.

4. Flood frequency analysis method is useful in flood risk assessment.

5. Remote sensing and Geoinformation Science techniques present elegant methods for flood monitoring and flood risk assessments

The information shown on the Flood Map can be used to assist in understanding the flood risk posed to a specific area of a community or even a specific property by community officials; real estate, insurance, and lending industry professionals; and Individual business owners and homeowners from it.The results of the study can be useful in providing early warning to local inhabitants of the potential risk involved in continuing to inhabit the delineated hazard zones.

The study revealedthat people living along the river bank, in the area, and people living in areas $1 \mathrm{~km}$ from the river bank are all at risk of potential flooding. It is advised that the river should be dredged and a levee built at the river bank in order to minimise the effect of flooding on the inhabitants of the area. 
Flood early warning signals should be put in place in order that the inhabitants of this area are not taken unawares, leading to prevention of huge loss of lives and properties.Evacuation to higher ground should be done early enough and medical facilities provided in the relief locations.Land use regulations should be enforced to prevent indiscriminate use of land and exposure of the area to factors that increase flood potential.

\section{REFERENCES}

[1] Kolawole, O.M., Olayemi, A.B and Ajayi, K.T (2011), Managing floods in Nigerian cities: Risk Analysis and adaptation options - Ilorin city as a case study, http://www. scholarresearchlibrary.com/archive.html (Archives of applied science research) 2011, 3(1):17-24

[2] Manandhar, B. (2010), Flood Plain Analysis and Risk Assessment of LotharKhola, A Master of Science Degree thesis submitted to the Institute of Forestry, Tribhuvan University. Phokara, Nepal. Retrieved at http://www.forestrynepal.org/images/thesis/b ikram\%20final_corrected.pdf, accessed $1 / 10 / 2013$

[3] Askew, A. J. (1999), Water in the International Decade for Natural Disaster Reduction. In Leavesley et al (eds.) Destructive Water: Water-caused Natural Disasters, their Abatement and Control. IAHS. Publication No. 239

[4] Edward Adebiyi R., 1997, The story of Ogunpa Flood in the Guardian Saturday May 17 , pp. 5

[5] Baiye E., 1988, Numan in the Throes of flood in the Guardian Thursday October 8, pp. 9

[6] Ehiorobo J. O. (2012), Sustainable flood risk assessment and flood management in Nigeria: obstacles, challenges and solutions, Speech/Lecture delivered on the occasion of the end of the year luncheon/AGM of the Nigerian Institution of civil Engineers on [14] , 2005, pp 1 - 13
Saturday December 15, 2012Etuonovbe A.K., The devastating effect of flooding in Nigeria, TS06J Hydrography and Environment, FIG working week 2011, Marrakech, Morocco 2011

[7] Ehiorobo J. O. and Izinyon O. C. (2011), Measurements and Documentation for Flood and Erosion Monitoring and Control in the Niger Delta States of Nigeria, TS07EEngineering Surveying, FIG Working Week 2011 Bridging the Gap between Cultures, Marrakech, Morocco, 18-22 May 2011

[8] Andersen, I., Dione O., Jarosewich-Holder, M. and Olivry, J. (2005); The Niger River Basin: A vision for Sustainable Management, The International bank for Reconstruction and development/World bank, Washington D.C (http://siteresources.worldbank.org/INTWA T/Resources/46021141206643460526/Niger _River_Basin_Vision_Sustainable_Manage ment.pdf) accessed 2/6/2013

[9] Ojha, G.S.P, Berndtsson, R. and Bhunya, P. (2008), Engineering Hydrology, $1^{\text {st }}$ edition, Oxford University Press, New Delhi, India

[10] Ehiorobo J.O., Izinyon O.C., (2013), Flood frequency Analysis at Oshun River in AsejireDam, Journal of Earth Sciences and Engineering, Volume 3, No. 5, May 2013, David Publishing Company, 9460 Telstar Ave. Suite 5, El Monte, CA 91731, USA.

[11] Chow, V.T., Maidment, D.R., Mays, L.W. (1988), Applied Hydrology, McGraw Hill Book Co., Singapore

[12] Ghosh, S.N., (2014), Flood control and Drainage Engineering, 4th Edition, CRC Press, Leiden, The Netherlands

[13] Goel, N.K., Htay, T. and Arya, D.S. (2005), Flood Hazard Mapping in the Lower part of Chindwin River Basin, Myanmar. Proceedings of International Conference In Innovation and Implementation of flood forecasting technology, Tromso, Norway, $17^{\text {th }}-19^{\text {th }}$ October 